\title{
O FATOR ESTRUTURAL ATUANTE NA CONEXÃO HIDRÁULICA SUBTERRÂNEA ENTRE O SISTEMA LACUSTRE DO BONFIM E A BACIA DO RIO PIRANGI, LITORAL LESTE DO RIO GRANDE DO NORTE
}

\author{
Leandson Roberto F. de Lucena ${ }^{1}$; Ernani Francisco da Rosa Filho²; Eduardo \\ Chemas Hindi ${ }^{2}$
}

\section{RESUMO}

Estudos de natureza estrutural realizados no litoral leste do Rio Grande do Norte, a sul da capital Natal, dão conta de uma complexa estruturação afetando toda a coluna lito-estratigráfica da área, envolvendo desde sedimentos cretácicos até depósitos quaternários, incluindo o Grupo Barreiras. Este arcabouço tectonoestrutural acha-se influenciando todo o contexto hidrogeológico, particularmente o Aqüífero Barreiras, através da configuração de variações de espessuras saturadas ou mesmo ocasionando o condicionamento de fluxos subterrâneos.

No presente artigo, utilizando-se dados geológicos, hidrogeológicos e geofísicos (eletro-resistividade), mostrou-se que a ocorrência de um aumento brusco do Aqüífero Barreiras, decorrente de falhamentos, entre o sistema lacustre do Bonfim e a bacia do Rio Pirangi (litoral sul de Natal-RN), propicia uma conexão hidráulica subterrânea entre os dois sistemas.

Esta conexão seria resultado da origem e canalização, através desta porção mais espessa do aqüífero, de um fluxo subterrâneo (no sentido da bacia do Rio Pirangi), decorrente da presença de cotas potenciométricas relativamente maiores nas proximidades da Lagoa do Bonfim, sobretudo durante e logo após o período chuvoso da região. Este fluxo é condicionado lateralmente por barreiras semiimpermeáveis do substrato carbonático (aqüitarde cretácico) do Aqüífero Barreiras.

\section{ABSTRACT}

Studies of structural nature accomplished at the east coast of the Rio Grande do Norte State, to south of its capital Natal, show a complex structuring affecting the whole lito-stratigraphic column of the area, involving from cretaceous sediments to

\footnotetext{
${ }^{1}$ Doutorando em Geologia Ambiental, Dpto. Geologia - UFPR, Centro Politécnico - Jd. das Américas - 81531990 - Curitiba-PR. Fone/Fax: (41)267-7910.

${ }^{2}$ LPH-UFPR, Centro Politécnico - Jd. das Américas - 81531-990 - Curitiba-PR. Fone/Fax: (41)267-7910. Email: ernani@geologia.ufpr.br.
} 
quaternary deposits, including the Barreiras Group. This tectonic-structural outline is influencing all hydrogeologic context, particularly the Barreiras Aquifer, through the configuration of variations of saturated thickness or even causing the conditioning of underground flows.

In the present article, using geological data, hydrogeologic and geophysical (electro-resistivity), it was shown that the occurrence of an abrupt increase of Barreiras Aquifer, due to faultings, between the Bonfim lacustrine system and Pirangi River basin (south coast of Natal-RN), it propitiates an underground hydraulic connection among the two systems.

This connection would be the result of the origin and canalization, through this thicker portion of the aquifer, of an underground flow (in the sense of Pirangi River basin), due to the presence of potentiometric quotas relatively larger in the proximities of the Bonfim lagoon, above all during and soon after the rainy period of the region. This flow is conditioned laterally by semi-impermeable barriers of the carbonated substratum (cretaceous aquitard) of Barreiras Aquifer.

PALAVRAS-CHAVE - Aqüífero Barreiras, hidrogeologia, sondagens elétricas, litoestratigrafia, fluxo subterrâneo.

\section{INTRODUÇÃO E OBJETIVOS}

Pesquisas envolvendo relações entre fenômenos hidrológicos e estruturais em terrenos sedimentares cenozóicos ainda se constituem num segmento recente nestas duas ciências. Lucena e Queiroz (1996), mostraram a delimitação de áreas com elevada transmissividade na zona sul de NatalRN, com base na associação dos abrangendo parte dos municípios de parâmetros litologia, hidrodinâmica e, Parnamirim, Nísia Floresta e São José principalmente, espessura do aqüífero, de Mipibú-RN (figura 1). 


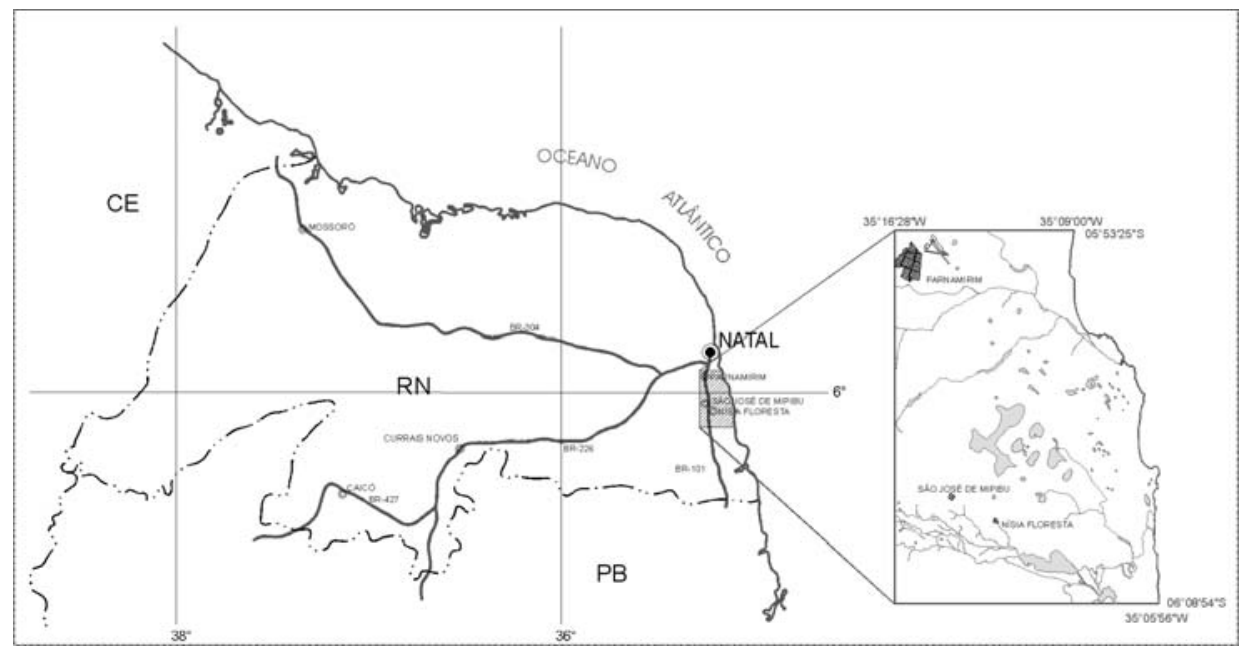

Figura 1 - Localização da área.

Os estudos realizados no âmbito do sistema lacustre do Bonfim elevam-se em importância na medida que se tem o mesmo atuando como fonte de abastecimento do sistema adutor Monsenhor Expedito, da Secretaria de Recursos Hídricos do Estado (SERHID$\mathrm{RN})$. Esta adutora é alimentada por uma captação direta no espelho d'água da Lagoa do Bonfim e por alguns poços tubulares situados a montante desta, sendo responsável pelo abastecimento d'água de diversas cidades do agreste potiguar. Dessa forma, uma quantificação consistente e monitoramento da disponibilidade hídrica do Sistema do Bonfim, torna-se imprescindível ao funcionamento de toda a adutora, sobretudo em períodos de estiagem prolongada. Por outro lado, levantamentos hidrogeológicos preliminares executados no extremo sul da bacia do Rio Pirangi, já nas proximidades da Lagoa do Bonfim, sugeriram a existência de uma conexão hidráulica entre ambos, fato que motivou o estudo ora abordado.

Dessa forma, o presente trabalho objetiva avaliar qualitativamente a possível conexão hidráulica subterrânea entre o sistema lacustre do Bonfim e a bacia do Rio Pirangi, além de subsidiar os órgãos governamentais gestores com informações adicionais no tocante à otimizar a avaliação do balanço hídrico do Sistema Lacustre do Bonfim.

\section{O CONTEXTO GEOLÓGICO E HIDROLÓGICO DA ÁREA}

A geologia da área é constituída estratigraficamente pelo embasamento cristalino Pré-cambriano, sotoposto a sedimentos cretácicos (este constituído por uma seqüência arenítica basal e outra carbonática no topo) e capeados por unidades cenozóicas, na qual 
apenas estas últimas são aflorantes. argilosos a conglomeráticos, até argilas. Dentre estas unidades cenozóicas, Esta composição diversificada, somada destacam-se o Grupo Barreiras (de à variações de espessuras saturadas idade Terciária-Quaternária) e toda a (geralmente decorrentes do arcabouço sedimentação quaternária, composta por tectono-estrutural da área), resultam em diversas gerações de dunas, coberturas vazões explotáveis igualmente variáveis, arenosas e sedimentos praiais e em geral de $5 \mathrm{~m}^{3} / \mathrm{h}$ a $100 \mathrm{~m}^{3} / \mathrm{h}$. A bacia aluvionares. O arcabouço tectono- do Rio Pirangi, localizada inteiramente estrutural é formado por uma complexa na meso-região Litoral Leste do Estado, estruturação regional (Bezerra et al, possui uma área de aproximadamente 1993; Lucena \& Queiroz, 1996; $430 \mathrm{~km}^{2}$. O índice pluviométrico da Coriolano et al, 1998), caracterizada em ordem de 1500 mm/ano (em média três direções principais: NW, NE e E-W, histórica), associado ao fato de estar aproximadamente, além de uma quarta esculpida totalmente em sedimentos do direção, menos expressiva e não Grupo Barreiras (considerando o individualizada em escala de mapa, com aqüífero homônimo influente), dão orientação geral N-S (figura 2). Estas origem a um sistema de drenagens direções estruturais foram denominadas perenes em praticamente toda sua de alinhamentos morfotectônicos ou extensão. O sistema lacustre do Bonfim mesmo falhamentos, quando possível a constitui-se numa pequena bacia com quantificação de rejeitos e/ou feições uma área aproximada de $60 \mathrm{~km}^{2}$, apropriadas no terreno.

O contexto hidrológico é constituído pelo Aqüífero Barreiras, a bacia do Rio Pirangi (ao norte) e o sistema lacustre do Bonfim (ao sul). O Aqüífero Barreiras, de caráter local livre a semi-confinado, é responsável pelo abastecimento da maioria das cidades da faixa litorânea oriental do Estado, incluindo a capital Natal. Apresenta-se, sob o ponto de vista litológico, bastante heterogêneo, envolvendo um conjunto de 6 lagoas principais (Bonfim, Urubu, Ferreira Grande, Redonda, Carcará e Boa Água) e um dreno que nasce na Lagoa do Urubu (Riacho Boa Cica). Os estudos disponíveis (Costa, 1997; Feitosa, 1997) classificam o sistema como uma bacia endorrêica, apesar do ponto de efluência do Riacho Boa Cica, sendo as lagoas consideradas exutórios das águas subterrâneas envolvendo desde arenitos pouco 


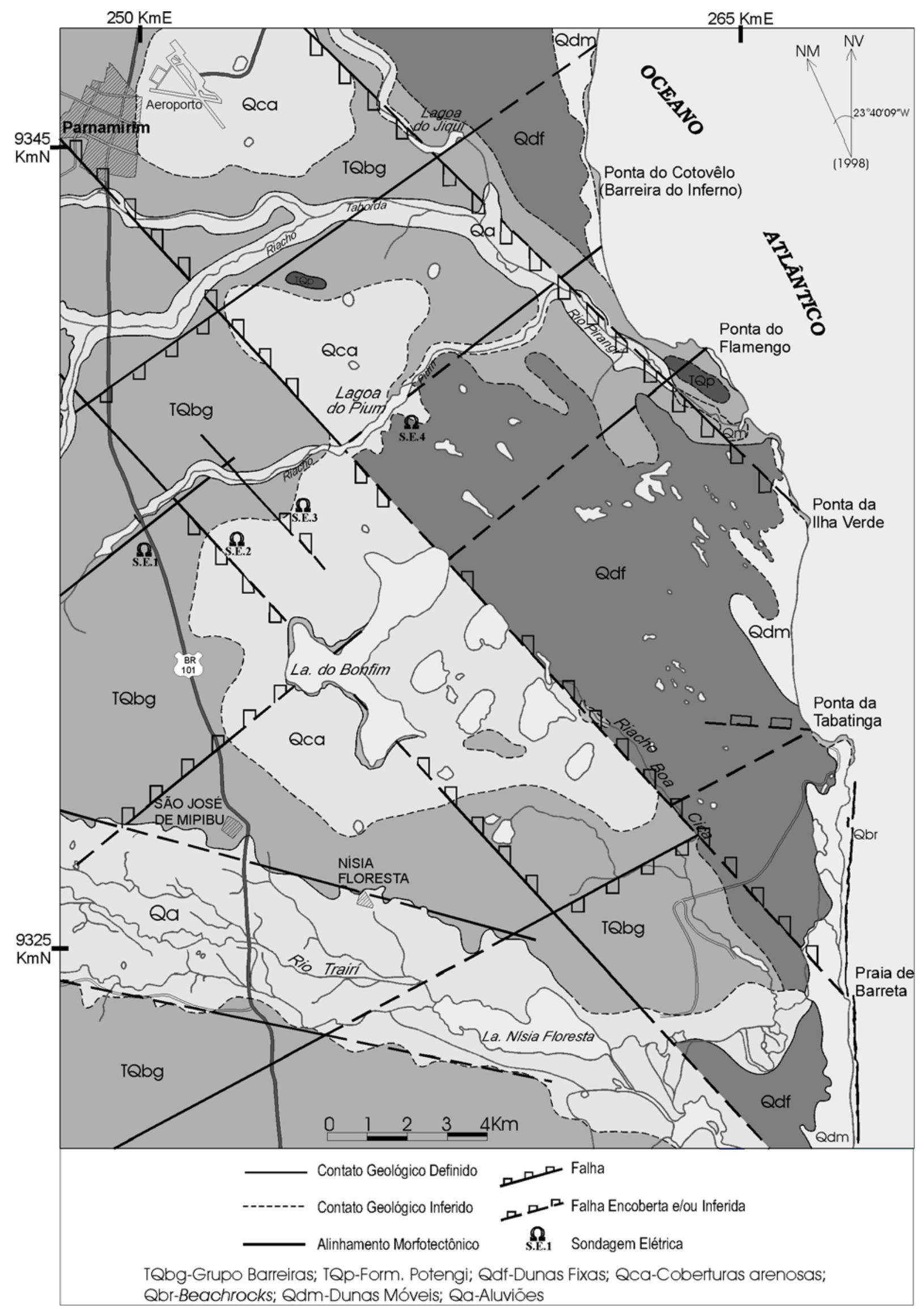

Figura 2 - Mapa geológico simplificado da área. 


\section{METODOLOGIA}

A partir da caracterização geológica prévia da área (litoestratigráfica e estrutural), foi executado um levantamento geo-elétrico, através de 4 sondagens elétricas, na área compreendida entre a Lagoa do Bonfim e o Riacho Pium (com lagoa homônima). O mesmo foi adotado tendo em vista sua notória aplicabilidade à hidrogeologia, somado ao fato da ausência de informações de poços locais. O objetivo final deste levantamento foi avaliar a possível conexão hidráulica subterrânea entre os dois sistemas.

De acordo com a necessidade de se adotar um modelo consistente com o ambiente geológico com vistas à interpretação de dados geo-elétricos, ressalta-se que a área estudada é constituída por terrenos sedimentares com estratificações aproximadamente horizontalizadas. Além disso, as distâncias entre as descontinuidades horizontais expressivas (falhas) são bem maiores que as máximas aberturas de eletrodos utilizadas. Dessa forma, o modelo geo-elétrico adotado possui as seguintes características:

i - O subsolo é constituído por uma seqüência de camadas com espessuras $\left(E_{i}\right)$ finitas, excetuando-se a última que é dada como infinita;

ii - Cada camada é admitida como sendo eletricamente homogênea e 90 isotrópica, sendo caracterizada por uma resistividade $\left(\rho_{\mathrm{i}}\right)$;

iii - As interfaces de separação entre as camadas são planas e horizontais e paralelas à superfície da terra.

Diante da inexistência de perfis elétricos de poços, que revelassem os valores de resistividades in situ dos diversos horizontes estratigráficos locais, adotou-se a estratégia de executar uma sondagem elétrica de "calibração", adjacente a um poço de perfil estratigráfico conhecido (situado na localidade de Bica em São José de Mipibu-RN, a sul da área de estudo e de propriedade da Companhia de Águas e Esgotos do Rio Grande do NorteCAERN). A interpretação desta sondagem foi feita fixando-se os valores de espessuras das camadas (fornecidas pelo perfil litológico) e estimando-se as resistividades, de maneira a ajustar a curva interpretada àquela de campo, usando valores característicos (dados bibliográficos) das respectivas litologias (Astier, 1975). As demais sondagens foram interpretadas quantitativamente mediante uma manutenção aproximada dos valores de resistividades das litologias desta calibração e variando-se o mínimo possível as respectivas espessuras, bem como admitindo-se uma razoável continuidade lateral das principais camadas geológicas. 
RESULTADOS E DISCUSSÃO

As sondagens geo-elétricas (figura

3) revelaram valores de resistividades da ordem de 50 a 600 Ohm.m, respectivamente para porções mais argilosas e arenosas do aqüífero, com base na sondagem geo-elétrica de da porção não saturada (com calibração. As sondagens apresentaram resistividades superiores a 1000 ainda proeminente influência da camada Ohm.m). condutiva basal, com resistividades da

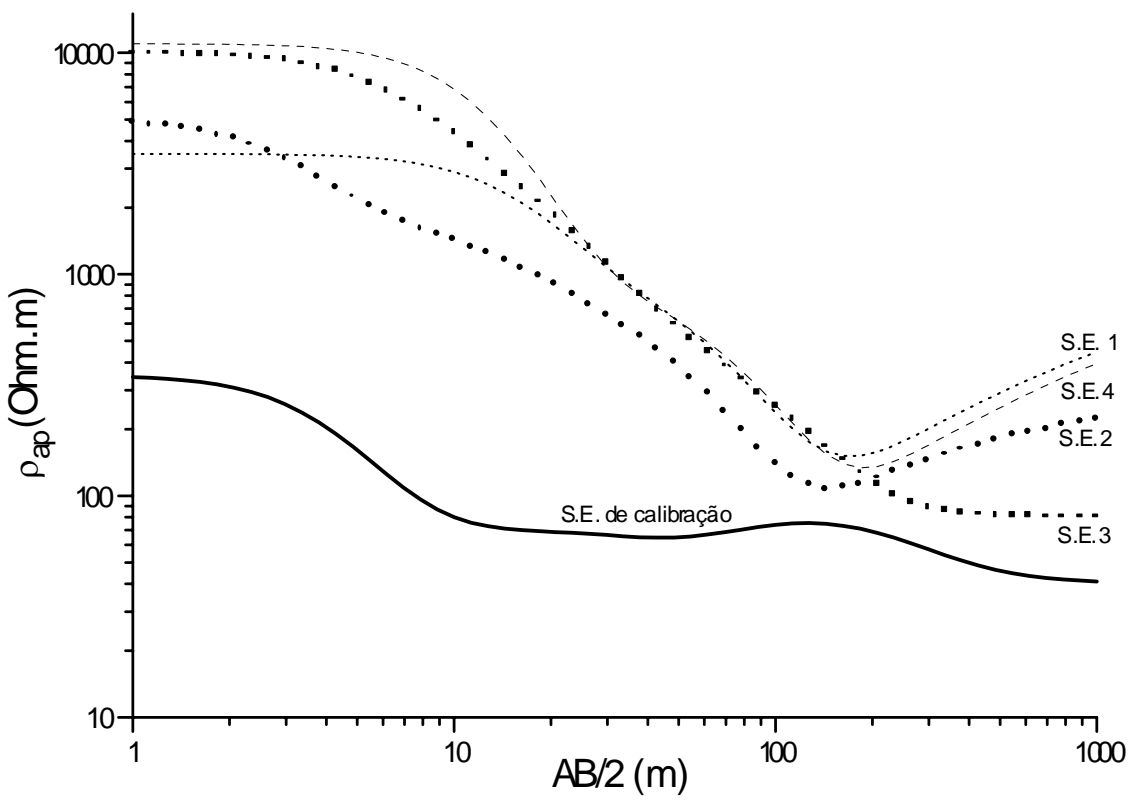

Figura 3 - Sondagens elétricas executadas.

No tocante aos limites subterrâneo Por outro lado, o limite subterrâneo, e superficial que separam o sistema especificamente, não é bem lacustre do Bonfim e a bacia hidrográfica caracterizado imediatamente a norte da do Rio Pirangi, verifica-se que os Lagoa do Bonfim, a julgar pelo mapa mesmos acompanham potenciométrico da área elaborado por aproximadamente um alinhamento Costa (1997) e visualizado na figura 4. morfotectônico local de direção nordeste. 


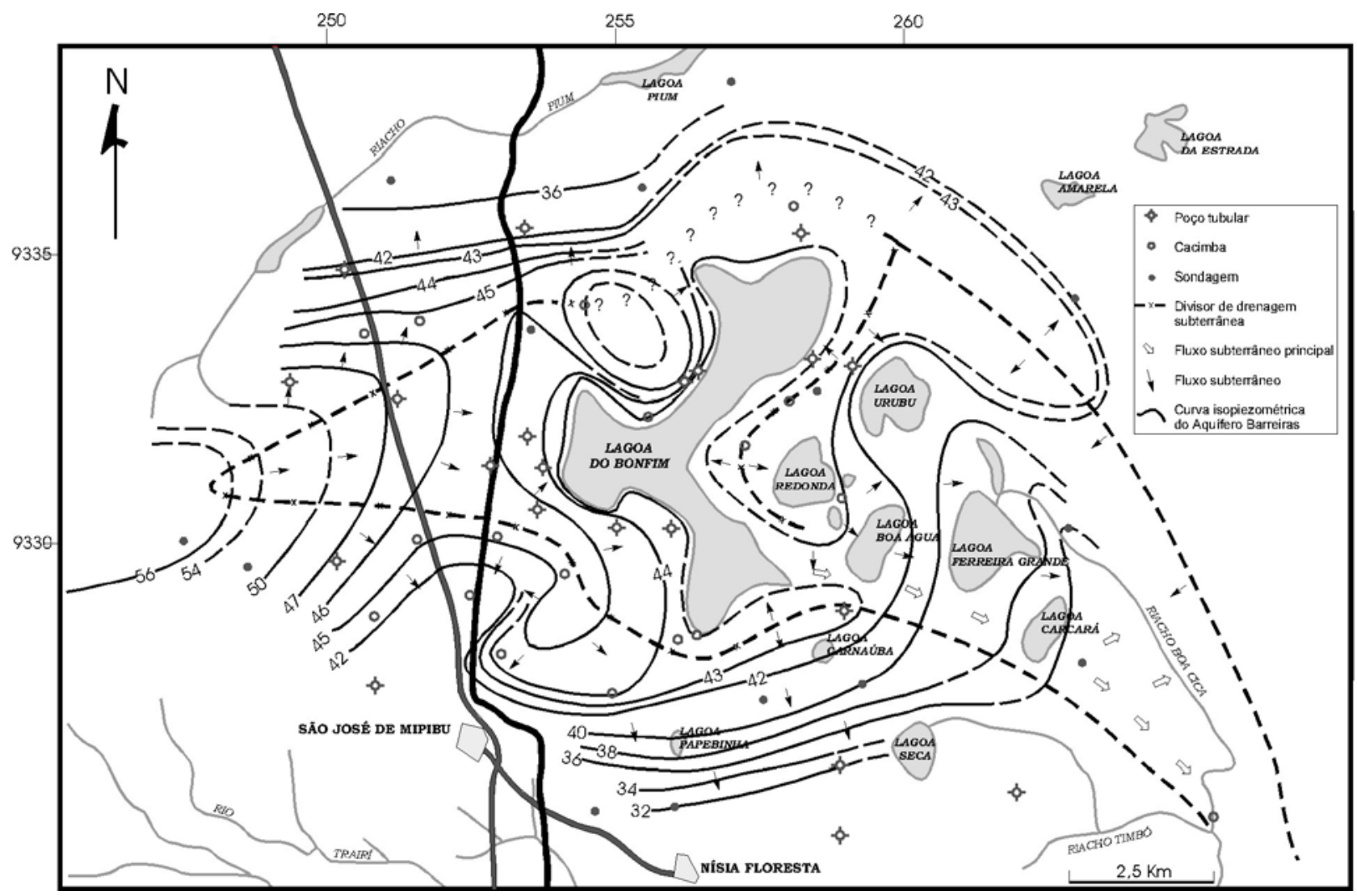

Figura 4 - Mapa potenciométrico da região da Lagoa do Bonfim, modificado de Costa (1997).

O referido alinhamento morfotectônico, situado entre a Lagoa do Bonfim e $o$ Riacho Pium/Lagoa homônima (ver mapa geológico simplificado da figura 2), é resultado da atuação de falhamentos que atingem o Grupo Barreiras e sedimentos mesozóicos na região, de acordo com a evolução tectono-estrutural desta (Bezerra et al, 1993; Lucena \& Queiroz, 1996; Coriolano et al, 1998) e caracterização de rejeitos verticais em perfis geológicos elaborados em toda a região (Lucena \& Queiroz, 1996). As evidências do alinhamento morfotectônico ora estudado como sendo decorrente de falhamentos 92 decorreu igualmente da caracterização de rejeitos verticais. Estes últimos foram caracterizados através da composição de uma seção hidrogeológica/geoelétrica, paralela ao citado limite e envolvendo as quatro sondagens elétricas (figura 5). 0 corte hidrogeológico/geo-elétrico resultante evidenciou um abatimento do substrato carbonático mesozóico do Grupo Barreiras, e conseqüente aumento brusco do aqüífero homônimo, da ordem de até 70 metros, disposto transversalmente ao limite entre a Lagoa do Bonfim e a bacia do Rio Pirangi.

Este movimento de blocos ocasiona, além do aumento de 
espessura do aqüífero neste bloco último teria sua origem relacionada com central, a configuração de barreiras a ocorrência de cotas potenciométricas laterais semi-impermeáveis, constituídas relativamente maiores nas proximidades pelo substrato carbonático do Grupo da Lagoa do Bonfim, fato este Barreiras (Aqüitard Cretácico), incrementado durante e logo após o resultando em limites subterrâneos período chuvoso da região (abril a localizados (Lucena, 1999) e agosto).

canalizando o fluxo subterrâneo. Este

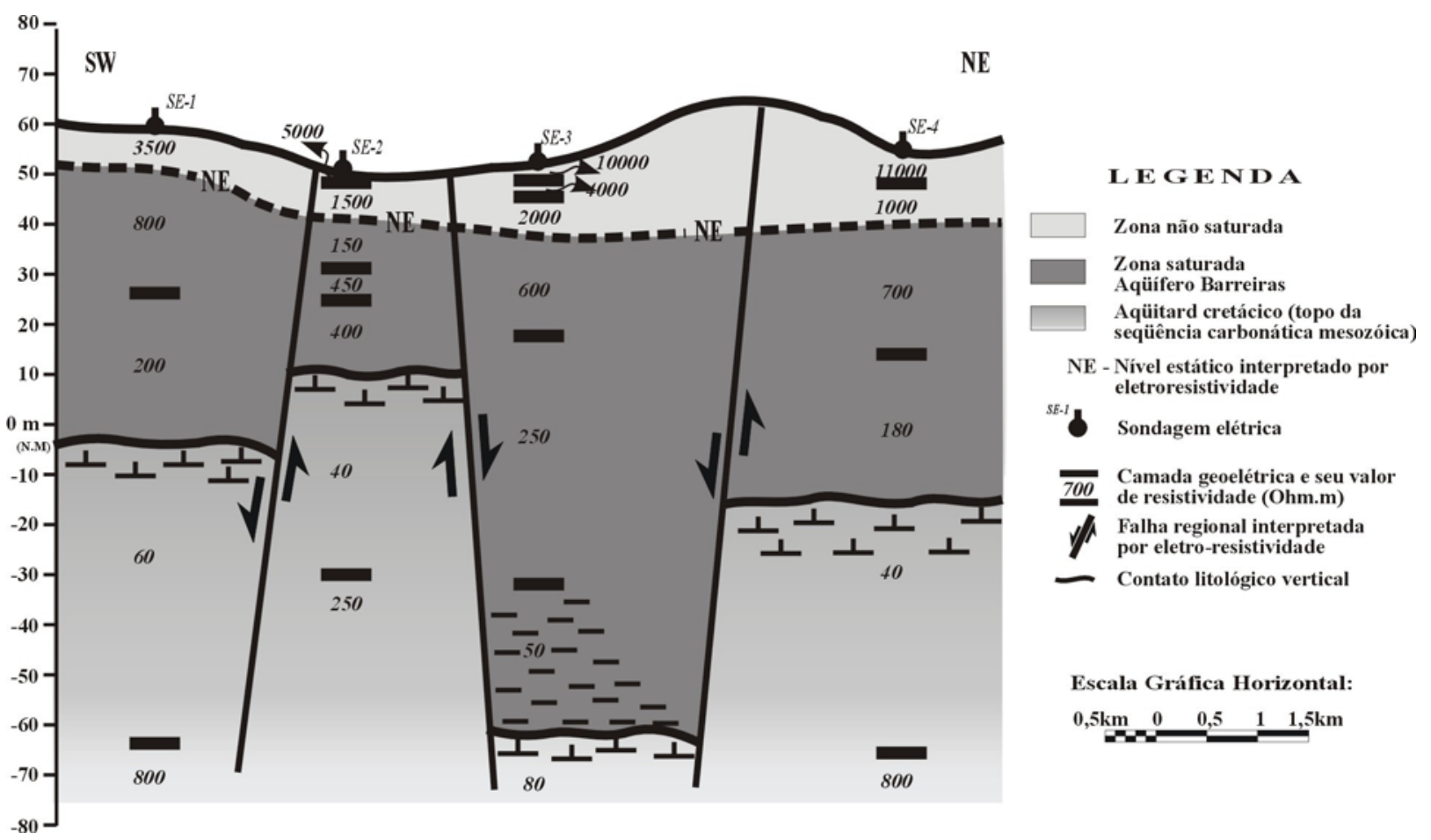

Figura 5 - Seção hidrogeológica, interpretada a partir de dados geo-elétricos (ver localização no mapa geológico da figura 2). As partes tracejadas do Aqüífero Barreiras indicam horizontes com maior percentual argiloso.

Tal observação encontra respaldo no mapa potenciométrico da figura 4 , o qual sugere implicitamente um fluxo secundário proveniente da Lagoa do Bonfim no sentido do Riacho Pium (Bacia do Rio Pirangi), ou mesmo a não Pium. configuração do limite subterrâneo nesse setor do mapa, conforme já reportado. Outras pesquisas em andamento dos autores do presente artigo confirmam preliminarmente a ocorrência de um alto potenciométrico relativo no extremo sul da bacia do Rio Pirangi, nas proximidades da Lagoa do Bonfim, com fluxo subterrâneo no sentido do Riacho 


\section{SÍNTESE CONCLUSIVA RECOMENDAÇÕES}

A conjunção de dados de natureza geológica, geo-elétrica e hidrogeológica confirmam a existência de um complexo arcabouço estrutural, afetando o Grupo Barreiras e aqǘfero homônimo, incluindo a área situada entre a Lagoa do Bonfim e o Riacho Pium/Lagoa do Pium (bacia do Rio Pirangi). A seção hidrogeológica elaborada entre os dois sistemas e interpretada a partir de dados geoelétricos, revela a ocorrência de um abatimento do bloco central desta seção, originando o aumento brusco de espessura saturada do Aqǘf́ero Barreiras, enquanto que as camadas semi-impermeáveis do Aqüitard Cretácico atuam como limites laterais de fluxo. A interação deste contexto físico (a presença de um meio de comunicação hidráulica subterrânea
E entre os dois sistemas), somado com a configuração de cotas potenciométricas relativamente maiores imediatamente ao norte da Lagoa do Bonfim, sobretudo no período chuvoso, ocasiona um fluxo subterrâneo secundário e localizado no sentido da bacia do Rio Pirangi.

As conclusões ora apresentadas devem ser encaradas como preliminares, tendo em vista a necessidade da realização de estudos mais aprofundados na região específica situada entre a Lagoa do Bonfim e o Riacho Pium/Lagoa do Pium (bacia do Rio Pirangi). Tais estudos devem contemplar um detalhamento do levantamento geológico e geo-elétrico da área, a elaboração de uma potenciometria local, bem como a perfuração de uma malha de piezômetros e monitoramento dos mesmos.

\section{REFERÊNCIAS BIBLIOGRÁFICAS}

ASTIER, J.L. 1975. Geofisica aplicada a la hidrogeologia. Madrid, Ed. Paraninfo. $344 \mathrm{p}$.

BEZERRA, F. H. R.; SAAD, A.; MOREIRA, J. A. M.; LINS, F. A. P. L.; NOGUEIRA, A. M. B.; MACEDO, J. W. P.; LUCENA, L. R. F. DE; NAZARÉ JR. D. 1993. Estruturação neotectônica do litoral de Natal-RN, com base na correlação entre dados geológicos, geomorfológicos e gravimétricos. In: SIMPÓSIO NACIONAL DE ESTUDOS TECTÔNICOS, IV. 1993, Belo Horizonte. Anais. Belo Horizonte-MG. SBG, Núcleo MG. Bol. 12: p. 317-321.

CORIOLANO, A.C.F.; LUCENA, L.R.F.; JARDIM DE SÁ, E.F.; SAADI, A. 1998. A deformação quaternária no litoral oriental do Rio Grande do Norte. In: SIMPÓSIO NACIONAL DE ESTUDOS TECTÔNICOS, VIII. Lençóis, 1998. Anais... Lençóis-BA, SBG. P. 67-70.

COSTA, W.D. 1997. Estudo da disponibilidade hídrica da Lagoa do Bonfim. In: SRH-RN. Costa Consultoria e Serviços Técnicos e Ambientais, Natal. 83 p. 
FEITOSA, E.C. 1997. Plano estadual de recursos hídricos do Rio Grande do Norte os recursos hídricos subterrâneos. In: SRH-RN. HIDROSERVICE Engenharia Ltda., Natal. Relatório diagnóstico, v. 1. 96 p.

LUCENA, L.R.F.; OLIVEIRA, S.K.; MEDEIROS, W.E.. 1999. Condicionamento estrutural sobre o Aqüífero Barreiras e Sistema Lacustre do Bonfim, Nísia Floresta-RN. In: INTERNATIONAL CONGRESS OF THE BRASILIAN GEOPHYSICAL SOCIETY, VI. Rio de Janeiro, 1999. Anais em CD... Rio de Janeiro-RJ, SBGf.

LUCENA, L.R.F. \& QUEIROZ, M.A. 1996. Considerações sobre as influências de uma tectônica cenozóica na pesquisa e prospecção de recursos hídricos - o exemplo do litoral sul de Natal-RN, Brasil. Revista Águas Subterrâneas, ABAS. Vol. 1, n 15: 81-88. 